\title{
Advances in salt tolerance molecular mechanism in tobacco plants
}

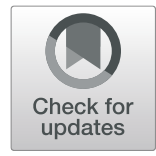

Haiji Sun ${ }^{1}$, Xiaowen Sun ${ }^{1}$, Hui Wang ${ }^{1}$ and Xiaoli Ma ${ }^{2^{*}}$ (D)

\begin{abstract}
Tobacco, an economic crop and important model plant, has received more progress in salt tolerance with the aid of transgenic technique. Salt stress has become a key research field in abiotic stress. The study of tobacco promotes the understanding about the important adjustment for survival in high salinity environments, including cellular ion transport, osmotic regulation, antioxidation, signal transduction and expression regulation, and protection of cells from stress damage. Genes, which response to salt, have been studied using targeted transgenic technologies in tobacco plants to investigate the molecular mechanisms. The transgenic tobacco plants exhibited higher seed germination and survival rates, better root and shoot growth under salt stress treatments. Transgenic approach could be the promising option for enhancing tobacco production under saline condition. This review highlighted the salt tolerance molecular mechanisms of tobacco.
\end{abstract}

Keywords: Salt tolerance, Transgenic technology, Gene, Tobacco

\section{Background}

Abiotic stress is the most harmful factor concerning the growth and productivity of crops worldwide, leading to enhanced accumulation of osmolytes, reduced photosynthesis, closure of stomata, and induction of stressresponsive genes [1-5]. Salt stress is one of the major abiotic stresses that have been related to the significant economic impact caused by the loss of arable land and the decline of agricultural productivity [6-8]. Salt stress caused the crop damages via ion balance, osmotic regulation and removal of reactive oxygen species [9-12]. Inducing these pathways through short-term exposure to low-salt stress, a process known as salt adaptation, can improve plant resistance to salt [13-15]. However, tolerance to soil salinity levels varies between plant species.

Tobacco (Nicotiana tabacum L.) is one of the main industrial crops and is widely grown in many countries. Tobacco is forming complex defenses to resist salt stress that rely on a variety of mechanisms [16-19]. Generally, salt stress in tobacco can be divided into ion toxicity, such as destroying plasma membrane structure, hindering the absorption of mineral elements, etc. and the

\footnotetext{
* Correspondence: mxl7125@126.com

${ }^{2}$ Central laboratory, Jinan Central Hospital Affiliated to Shandong University, Jinan 250013, China

Full list of author information is available at the end of the article
}

secondary stress effect, such as oxidative stress, drought stress, etc. [20, 21]. In this review, the recent advances on the mechanism of salt tolerance in tobacco were summarized in order to provide data for the study of salt tolerance and the adjustment of planting layout in tobacco.

\section{Ion transport genes related to tobacco salt tolerance}

The activities of ion transporters or antiporters localized in the plasma membrane and vacuolar membrane are essential for tobacco growth and development [22-24]. Intracellular regionalization of toxic ions using specific transporter proteins is a key pattern used by tobacco to maintain a moderate cytosolic $\mathrm{K}^{+} / \mathrm{Na}^{+}$ratio in the cytosol. The high-affinity potassium ion transporter protein selectively absorbs $\mathrm{K}^{+}$from the environment to balance the ratio of $\mathrm{Na}^{+} / \mathrm{K}^{+}$in cells and prevent the toxicity of excessive $\mathrm{Na}^{+}$content to cells [25-28]. Constitutive expression of potassium transporter OsHAK5 in culturedtobacco BY2 (Nicotiana tabacum cv. Bright Yellow 2) cells enhanced the accumulation of $\mathrm{K}^{+}$but not $\mathrm{Na}^{+}$in the cells during salt stress and conferred increased salt tolerance to the cells, suggesting that the plasmamembrane localized $\mathrm{Na}^{+}$insensitive $\mathrm{K}^{+}$transporters could be used as a tool to enhance salt tolerance in tobacco [29]. $\mathrm{Na}^{+}$transporter protein (SKC) can transport 
$\mathrm{Na}^{+}$exclusively, but does not participate in the transport of other cations such as $\mathrm{K}^{+}$, and plays an important role in resisting abiotic stress [30-32]. The survival rate and root length of SbSKC1 transgenic tobacco plants under $\mathrm{NaCl}$ stress were significantly higher than those of the control [33]. The activities of superoxide dismutases (SOD), catalase (CAT), and pero-xidase (POD) enzymes were increased, and the salt tolerance of transgenic tobacco plants was strengthened [34].

$\mathrm{Na}^{+} / \mathrm{H}+$ reverse proteins are mainly located in the vacuole membrane and cytoplasmic membrane, which are called vacuolar $\mathrm{Na}+/ \mathrm{H}+$ reverse transporter (V-type and P-type) [35]. $\mathrm{Na}^{+} / \mathrm{H}^{+}$antiporters (NHXs) are integral membrane transporters that catalyze the electroneutral exchange of $\mathrm{K}^{+} / \mathrm{Na}^{+}$for $\mathrm{H}^{+}$and are implicated in cell expansion, development, $\mathrm{pH} /$ ion homeostasis and salt tolerance [36, 37]. Different NHX isoforms have been overexpressed in variety of plant species showed substantial salt tolerance. NHX1 had functions in regulating the $\mathrm{pH}$ in the vacuole and cellular ROS level, which could prime the antioxidative system [38, 39]. Arabidopsis AtNHX1, the first tonoplast $\mathrm{Na}^{+} / \mathrm{H}^{+}$exchanger identified in plants, mediates $\mathrm{Na}^{+} / \mathrm{H}^{+}$exchange activity in plant vacuoles [40]. Overexpression of AtNHX confers salt tolerance in Arabidopsis plants and salt tolerance correlates with increased vacuolar $\mathrm{Na}^{+} / \mathrm{H}^{+}$exchange activity and vacuolar sodium accumulation. LfNHX1 protein sequence showed high similarity with NHX1 homologs reported from other halophyte plants. The overexpression of LfNHX1 gene under CaMV35S promoter conferred salt and drought tolerance in tobacco plants [41, 42]. NbNHX1 silencing led to a lower $\mathrm{pH}$ in the vacuole and a lower cellular ROS level in N. benthamiana, which was coupled with a decreased $\operatorname{NAD}(\mathrm{P})(\mathrm{H})$ pool and decreased expression of ROSresponsive genes [43]. Overexpression of SeNHX1 intensified the compartmentation of $\mathrm{Na}+$ into vacuole under salt stress and improved the ability of eliminating ROS after pathogen attack, which then enhanced salt tolerance and disease resistance simultaneously in tobacco [44]. SeNHX1, AtNHX1, sbNHX1 and NbNHX1 transgenic tobaccos exhibited more biomass, longer root length, and higher $\mathrm{Na}+/ \mathrm{H}+$ ratio under $\mathrm{NaCl}$ treatment, indicating enhanced salt tolerance [45].

\section{Osmotic regulation genes related to tobacco salt tolerance}

Betaine is a water-soluble alkaloid in plants and has a strong affinity as an osmotic regulator [46]. The exogenous application of glycine betaine upregulates many proteins including PSII, Rubisco and superoxide dismutase when plants are subjected to $\mathrm{NaCl}$ stress [47, 48]. In general, the main synthetic pathway of betaine in plants is to produce betaine aldehyde catalyzed by choline monooxygenase (CMO) and then by betaine aldehyde dehydrogenase (BADH) [49]. The transgenic tobacco plants transferred by CMO gene of Salicornia salsa could grow normally under salt stress [50]. By introducing rice OsCMO gene into tobacco, it was found that the transgenic tobacco plants increased and the tolerance to salt stress increased [51]. Genetically engineered tobacco was established for the biosynthesis of glycine betaine in vivo and this tobacco showed increased tolerance of photosynthesis to salt stress.

Proline is small molecular organic compound that has been demonstrated to play a protective role in defending against high salinity stresses [52]. Under salt stress, plant tissues accumulate proline to alleviate the toxic effect of excessive ammonia on the organism, scavenge free radicals to protect the integrity of plasma membrane and regulate osmotic pressure to prevent the change of plasma membrane permeability [53]. Glutamic acid, the biosynthetic precursor of proline, mainly comes from glutamine synthase-glutamic acid synthase (GSGOGAT). Plant glutamine synthase has many isoenzymes, which can be divided into cytosolic glutamine synthase (GS1) and plastid glutamine synthase (GS2) [54]. Over-expression of TaGS1/TaGS2 in tobacco could increase proline content, nitrogen use efficiency and salt tolerance under salt stress [55]. The transgenic tobacco plant over-expressing CsGSTs exhibited both drought and salinity stress tolerance [56].

\section{Reactive oxygen species (ROS) detoxification genes related to tobacco salt tolerance}

Tobacco plants accumulate a large number of reactive oxygen species under stress [57]. ROS detoxification plays a protective role in response to salt stress by scavenging toxic radicals $[58,59]$. Antioxidative defense systems include both non-enzymatic and enzymatic components, including superoxide dismutases (TaSOD) [60], monodehydroascorbate reductase (MDAR) [61], glutathione transferases (SbGST, SsGST) [62, 63], ascorbate peroxidases (SssAPX and PtcAPX) [64, 65]. They have been shown to play important roles in protecting against salt-induced oxidative stress. Gene engineering was used to express ROS scavenger factor to improve salt resistance in Tobacco plants [66].

The transcription of AhCuZnSOD gene in transgenic tobacco plants was up-regulated under abiotic stresses such as salt, drought, high salinity, cold and oxidative stress, which increased SOD activity and improved oxidative damage under abiotic stress [67]. When LetAPX gene was transferred into tobacco, the activity of APX in transgenic tobacco plants increased significantly, the germination rate of tobacco seeds increased, and the tolerance to salt stress increased [68]. 2-Cys peroxidoreductases has the ability to scavenge ROS in the chloroplast. Transforming the gene 
into tobacco can increase SOD activity, inhibit APX activity, enhance the stability of photosynthetic electron transport chain under high salt environment, and reduce the photoinhibition degree of PSII [69].

\section{Signal transduction genes related to tobacco salt tolerance}

Studies have shown that transcription factors (TFs), such as AP2/ERF and WRKY, play an important role in abiotic stress and mediate the diversity of signal transduction processes induced by abiotic stresses such as salt, oxidation, cold and drought $[70,71]$. AP2/ERF is a large group of plant-specific TFs and could be classified into four major subfamilies: the AP2, RAV, ERF, and Dehydration responsive element binding protein (DREB) subfamilies [72, 73]. Many ERF genes are reported to be involved in responses to salinity/drought. JcERF1 gene from Jatropha curcas was introduced into tobacco, which could enhance the salt tolerance of tobacco [74]. It was found that the salt tolerance of LchERF transgenic tobacco was improved. When ERF76 gene was introduced into tobacco, the germination rate, root length, fresh weight, SOD, POD activity and proline content of transgenic tobacco seeds increased under salt stress, and the salt tolerance of tobacco was improved [75]. DREB transcription factors involved in the progress of salt tolerance related genes in tobacco via plant stress response signaling [76].

WRKY transcription factors are new transcription regulators with highly conserved amino acid sequences at the $\mathrm{N}$-terminal found in plants, which can specifically interact with TGAC sequences, regulate the expression of regulatory genes and functional genes with w-box elements in promoters, and play an important role in abiotic stress $[77,78]$. In transgenic tobacco, overexpression of SpWRKY1, GhWRKY25, and TaWRKY44 promotes tolerance to salt and drought stress [79].

Zinc finger proteins comprise a family of transcription factors, mainly through the combination with $\mathrm{Zn}^{2+}$ to maintain a self forming "finger" structure domain, participating in the regulation of gene expression. The transcription factors of zinc finger proteins can be divided into $\mathrm{C} 2 \mathrm{H} 2, \mathrm{C} 2 \mathrm{C} 2$ and $\mathrm{C} 2 \mathrm{HC}$, among which $\mathrm{C} 2 \mathrm{H} 2$ is the most abundant zinc finger protein in eukaryote genome [80, 81]. Citrus PtrZPT2-1 was introduced into tobacco, the osmotic adjustment solute increased and the hydrogen peroxide decreased, which enhanced the cold, drought and salt tolerance of tobacco plants [82].

In addition, calcium-dependent protein kinase synthesis pathways (CDPKs) play an important role in the downstream effect of calcium signaling. ZoCDPK1 gene can increase salt tolerance of tobacco, and the up regulation of ZoCDPK1 expression level in tobacco is related to RD21A and ERD1 genes related to stress [83, 84]. Mitogen-activated protein kinase (MAPK) cascades play key roles in the transduction of hormone signals, plant cytokinesis, pollen development, and biotic and abiotic stresses $[85,86]$. The overexpression of the PtMAPKK4 enhanced the activity of antioxidant enzyme through an up-regulation of its expression, and the reduction of reactive oxygen species (ROS) could improve the plant tolerance of stress [87]. Furthermore, accumulating

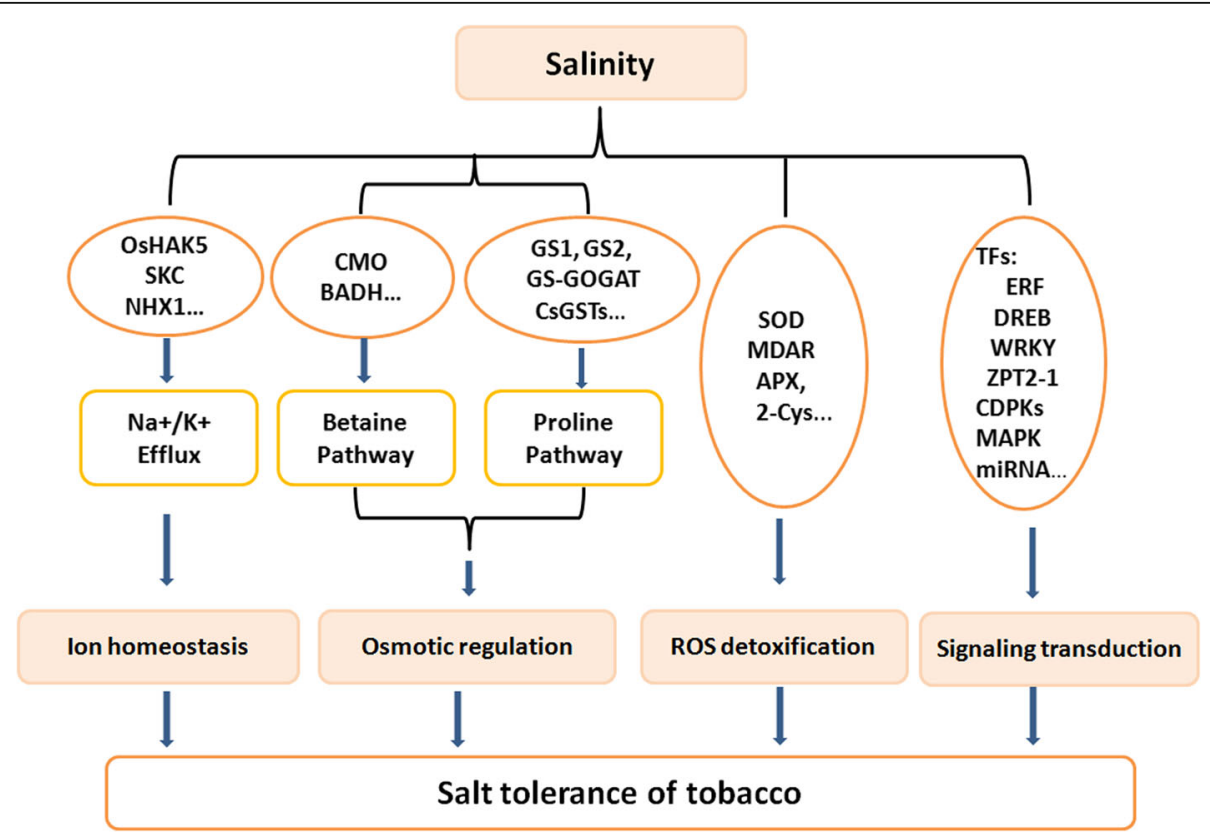

Fig. 1 A proposed model of molecular mechanism of tobacco in response to salt stress 
evidence suggests that miRNAs, key enzyme genes for sterol synthesis of Brassinol, hormonal regulation and resistance $(\mathrm{R})$ genes play essential roles in both abiotic and biotic stress responses in tobacco plants [88-91].

\section{Conclusions}

Salinity is the serious problem for agricultural productivity as many countries are facing this problem. Tobacco has recently been investigated as a potential model crop to adapt to salt stress via various strategies to cope with cellular ion homeostasis, osmotic pressure, antioxidation and signaling transduction regulation. Based on the studies focused on the molecular mechanisms associated with stress responses, a common set of proteins and regulatory pathways contribute to adaptation in tobacco plants (Fig. 1). A clearer idea of the mechanisms that contribute to salt tolerance in tobacco plants would facilitate their application in improving organismal tolerance to salinity stress. The combination of conventional and advance molecular technology is conducive to the study of salt-tolerant varieties.

\footnotetext{
Abbreviations

APX: Ascorbate peroxidase; BADH: Betaine aldehyde dehydrogenase; CAT: Catalase; CDPKs: Calcium-dependent protein kinase; CMO: Choline monooxygenase; DREB: Dehydration responsive element binding protein; ERF: Ethylene response factor; GS1: Cytosolic glutamine synthase; GS2: Plastid glutamine synthase; GS-GOGAT: Glutamine synthase-glutamic acid synthase; GST: Glutathione transferase; MDAR: Monodehydroascorbate reductase; POD: Pero-xidase; ROS: Reactive oxygen species; SKC: Na + transporter protein; SOD: Superoxide dismutases; TFs: Transcription factors; MAPK: Mitogen-activated protein kinase
}

\section{Acknowledgments}

The authors thank the funding agencies for support.

\section{Authors' contributions}

Haiji Sun wrote the main part of the review. Xiaowen Sun and Hui Wang collected and summarized the related references. Xiaoli Ma coordinated the writing process and edited the review. All authors made the final editing of the review and approved the final manuscript.

\section{Funding}

This work was supported by the National Natural Science Foundation of China (No. 31672286) and the Natural Science Foundation of Shandong Province, China (ZR2018MH021).

\section{Availability of data and materials}

Not applicable.

Ethics approval and consent to participate

Not applicable.

\section{Consent for publication}

Not applicable.

\section{Competing interests}

The authors declare that they have no competing interests.

\section{Author details}

${ }^{1}$ School of Life Science, Shandong Normal University, Jinan 250014, China. ${ }^{2}$ Central laboratory, Jinan Central Hospital Affiliated to Shandong University, Jinan 250013, China.
Received: 6 September 2019 Accepted: 18 February 2020

Published online: 24 February 2020

\section{References}

1. Zheng Y, Liao C, Zhao S, Wang C, Guo Y. The Glycosyltransferase QUA1 regulates chloroplast-associated calcium signaling during salt and drought stress in Arabidopsis. Plant Cell Physiol. 2017;58(2):329-41.

2. Zhang LY, Zhang XJ, Fan SJ. Meta-analysis of salt-related gene expression profiles identifies common signatures of salt stress responses in Arabidopsis. Plant Syst Evol. 2017;303(6):757-74.

3. Sui N, Tian SS, Wang WQ, Wang MJ, Fan H. Overexpression of Glycerol-3phosphate Acyltransferase from Suaeda salsa improves salt tolerance in Arabidopsis. Front Plant Sci. 2017:8:1337.

4. Zhang YJ, Kong XQ, Dai JL, Luo Z, Li ZH, Lu HQ, Xu SZ, Tang W, Zhang DM, Li WJ, et al. Global gene expression in cotton (Gossypium hirsutum L.) leaves to waterlogging stress. PLoS One. 2017;12(9):e0185075.

5. Sun S, Zhou J. Molecular mechanisms underlying stress response and adaptation. Thoracic cancer. 2018;9(2):218-27.

6. Guo JR, Li YD, Han GL, Song J, Wang BS. NaCl markedly improved the reproductive capacity of the euhalophyte Suaeda salsa. Funct Plant Biol. 2018;45(3):350-61

7. Wang JS, Zhang Q, Cui F, Hou L, Zhao SZ, Xia H, Qiu JJ, Li TT, Zhang Y, Wang XJ, et al. Genome-wide analysis of gene expression provides new insights into cold responses in Thellungiella salsuginea. Front Plant Sci. 2017:8:1-12

8. Song J, Zhou JC, Zhao WW, Xu HL, Wang FX, Xu YG, Wang L, Tian CY. Effects of salinity and nitrate on production and germination of dimorphic seeds applied both through the mother plant and exogenously during germination in Suaeda salsa. Plant Species Biology. 2016;31(1):19-28.

9. Zhou JC, Fu TT, Sui N, Guo JR, Feng G, Fan JL, Song J. The role of salinity in seed maturation of the euhalophyte Suaeda salsa. Plant Biosystems. 2016; 150(1):83-90.

10. Yang S, Li L, Zhang J, Geng Y, Guo F, Wang J, Meng J, Sui N, Wan S, Li X. Transcriptome and differential expression profiling analysis of the mechanism of $\mathrm{Ca}(2+)$ regulation in Peanut (Arachis hypogaea) pod development. Front Plant Sci. 2017;8:1609.

11. Sui N, Wang Y, Liu S, Yang Z, Wang F, Wan S. Transcriptomic and physiological evidence for the relationship between unsaturated fatty acid and salt stress in Peanut. Front Plant Sci. 2018;9:7.

12. Deinlein U, Stephan AB, Horie T, Luo W, Xu G, Schroeder Jl. Plant salttolerance mechanisms. Trends Plant Sci. 2014;19(6):371-9.

13. Song J, Shi WW, Liu RR, Xu YG, Sui N, Zhou JC, Feng G. The role of the seed coat in adaptation of dimorphic seeds of the euhalophyte Suaeda salsa to salinity. Plant Species Biol. 2017;32(2):107-14.

14. Kong XQ, Wang T, Li WJ, Tang W, Zhang DM, Dong HZ. Exogenous nitric oxide delays salt-induced leaf senescence in cotton (Gossypium hirsutum L.). Acta Physiol Plant. 2016; 38(3):1-9.

15. Wang FX, Xu YG, Wang S, Shi WW, Liu RR, Feng G, Song J. Salinity affects production and salt tolerance of dimorphic seeds of Suaeda salsa. Plant Physiol Biochem. 2015;95:41-8.

16. Tang GY, Shao FX, Xu PL, Shan L, Liu ZJ. Overexpression of a peanut NAC gene, AhNAC4, confers enhanced drought tolerance in tobacco. Russ J Plant Physiol. 2017;64(4):525-35.

17. Tang GY, Wei LQ, Liu ZJ, Bi YP, Shan L. Ectopic expression of peanut acyl carrier protein in tobacco alters fatty acid composition in the leaf and resistance to cold stress. Biol Plant. 2012;56(3):493-501.

18. Guo F, Liu C, Xia H, Bi Y, Zhao C, Zhao S, Hou L, Li F, Wang X. Induced expression of AtLEC1 and AtLEC2 differentially promotes somatic embryogenesis in transgenic tobacco plants. PLoS One. 2013:8(8):e71714.

19. Ganesan G, Sankararamasubramanian HM, Harikrishnan M, Ganpudi A, Parida A. A MYB transcription factor from the grey mangrove is induced by stress and confers $\mathrm{NaCl}$ tolerance in tobacco. J Exp Bot. 2012:63(12):4549-61.

20. Cao SW, Huang JL, Chen J, Hu YW, Hu XM, Ren TY, Zheng SH, Lin JD, Tang $J$, Zheng L, et al. Long non-coding RNA UBE2CP3 promotes tumor metastasis by inducing epithelial-mesenchymal transition in hepatocellular carcinoma. Oncotarget. 2017:8(39):65370-85

21. Sharma V, Goel P, Kumar S, Singh AK. An apple transcription factor, MdDREB76, confers salt and drought tolerance in transgenic tobacco by activating the expression of stress-responsive genes. Plant Cell Rep. 2019; 38(2):221-41. 
22. Lu M, Zhang YY, Tang SK, Pan JB, Yu YK, Han J, Li YY, Du XH, Nan ZJ, Sun QP. AtCNGC2 is involved in jasmonic acid-induced calcium mobilization. J Exp Bot. 2016;67(3):809-19.

23. Gouiaa S, Khoudi H, Leidi EO, Pardo JM, Masmoudi K. Expression of wheat $\mathrm{Na}(+) / H(+)$ antiporter TNHXS1 and $\mathrm{H}(+)$ - pyrophosphatase TVP1 genes in tobacco from a bicistronic transcriptional unit improves salt tolerance. Plant Mol Biol. 2012;79(1-2):137-55.

24. Feng ZT, Sun QJ, Deng YQ, Sun SF, Zhang JG, Wang BS. Study on pathway and characteristics of ion secretion of salt glands of Limonium bicolor. Acta Physiol Plant. 2014;36(10):2729-41.

25. Deng YQ, Bao J, Yuan F, Liang X, Feng ZT, Wang BS. Exogenous hydrogen sulfide alleviates salt stress in wheat seedlings by decreasing Na+ content. Plant Growth Regul. 2016;79(3):391-9.

26. Feng ZT, Deng YQ, Fan $\mathrm{H}$, Sun QJ, Sui N, Wang BS. Effects of $\mathrm{NaCl}$ stress on the growth and photosynthetic characteristics of Ulmus pumila L. seedlings in sand culture. Photosynthetica. 2014;52(2):313-20.

27. Zhang T, Song J, Fan JL, Feng G. Effects of saline-waterlogging and dryness/ moist alternations on seed germination of halophyte and xerophyte. Plant Species Biology. 2015;30(3):231-6.

28. Li X, Liu Y, Chen M, Song YP, Song J, Wang BS, Feng G. Relationships between ion and chlorophyll accumulation in seeds and adaptation to saline environments in Suaeda salsa populations. Plant Biosystems. 2012;146:142-9.

29. Horie T, Sugawara M, Okada T, Taira K, Kaothien-Nakayama P, Katsuhara M, Shinmyo A, Nakayama H. Rice sodium-insensitive potassium transporter, OsHAK5, confers increased salt tolerance in tobacco BY2 cells. J Biosci Bioeng. 2011;111(3):346-56.

30. Yuan F, Leng BY, Wang BS. Progress in studying salt secretion from the salt glands in Recretohalophytes: how do plants secrete salt? Front Plant Sci. 2016;7:1-11.

31. Feng ZT, Deng YQ, Zhang SC, Liang X, Yuan F, Hao JL, Zhang JC, Sun SF, Wang BS. K+ accumulation in the cytoplasm and nucleus of the salt gland cells of Limonium bicolor accompanies increased rates of salt secretion under $\mathrm{NaCl}$ treatment using NanoSIMS. Plant Sci. 2015;238:286-96.

32. Song J, Shi GW, Gao B, Fan H, Wang BS. Waterlogging and salinity effects on two Suaeda salsa populations. Physiol Plant. 2011;141(4):343-51.

33. YAO X, LIU Y, ZHAO D. Cloning of Nat transporter protein SbSKC1 gene from Sorghum and identification of its salt-resistant function in tobacco. Acta Agron Sin. 2017:43(2):190-200.

34. Yuan F, Lyu MJA, Leng BY, Zhu XG, Wang BS. The transcriptome of $\mathrm{NaCl}$ treated Limonium bicolor leaves reveals the genes controlling salt secretion of salt gland. Plant Mol Biol. 2016;91(3):241-56.

35. Zhou Y, Lai Z, Yin X, Yu S, Xu Y, Wang X, Cong X, Luo Y, Xu H, Jiang X. Hyperactive mutant of a wheat plasma membrane $\mathrm{Na}(+) / \mathrm{H}(+)$ antiporter improves the growth and salt tolerance of transgenic tobacco. Plant Sci. 2016;253:176-86.

36. Jegadeeson V, Kumari K, Pulipati S, Parida A, Venkataraman G. Expression of wild rice Porteresia coarctata PcNHX1 antiporter gene (PcNHX1) in tobacco controlled by PCNHX1 promoter (PcNHX1p) confers $\mathrm{Na}(+)$-specific hypocotyl elongation and stem-specific $\mathrm{Na}(+)$ accumulation in transgenic tobacco. Plant Physiol Biochem. 2019;139:161-70.

37. Conde A, Chaves MM, Geros H. Membrane transport, sensing and signaling in plant adaptation to environmental stress. Plant Cell Physiol. 2011;52(9): 1583-602.

38. Tiwari V, Patel MK, Chaturvedi AK, Mishra A, Jha B. Cloning and functional characterization of the $\mathrm{Na}(+) / \mathrm{H}(+)$ antiporter $(\mathrm{NHX} 1)$ gene promoter from an extreme halophyte Salicornia brachiata. Gene. 2019;683:233-42.

39. Zhou S, Chen X, Zhang X, Li Y. Improved salt tolerance in tobacco plants by co-transformation of a betaine synthesis gene BADH and a vacuolar $\mathrm{Na}+$ / $\mathrm{H}+$ antiporter gene SeNHX1. Biotechnol Lett. 2008;30(2):369-76.

40. Apse MP, Aharon GS, Snedden WA, Blumwald E. Salt tolerance conferred by overexpression of a vacuolar $\mathrm{Na}+/ \mathrm{H}+$ antiport in Arabidopsis. Science. 1999; 285(5431):1256-8.

41. Han N, Shao Q, Bao HY, Wang BS. Cloning and characterization of a Ca2+/ H+ Antiporter from halophyte Suaeda salsa L. Plant Mol Biol Report. 2011; 29(2):449-57.

42. Rauf M, Shahzad K, Ali R, Ahmad M, Habib I, Mansoor S, Berkowitz GA, Saeed NA. Cloning and characterization of $\mathrm{Na}+/ \mathrm{H}+$ antiporter (LfNHX1) gene from a halophyte grass Leptochloa fusca for drought and salt tolerance. Mol Biol Rep. 2014;41(3):1669-82.

43. Chen $X$, Bao H, Guo J, Jia W, Tai F, Nie L, Jiang P, Feng J, Lv S, Li Y. Na(+ )$/ H(+)$ exchanger 1 participates in tobacco disease defence against
Phytophthora parasitica var. nicotianae by affecting vacuolar $\mathrm{pH}$ and priming the antioxidative system. J Exp Bot. 2014;65(20):6107-22.

44. Chen X, Bao H, Guo J, Jia W, Li Y. Overexpression of SeNHX1 improves both salt tolerance and disease resistance in tobacco. Plant Signal Behav. 2015; 10(4):e993240

45. Duan $X$, Song $Y$, Yang A, Zhang J. The transgene pyramiding tobacco with betaine synthesis and heterologous expression of AtNHX1 is more tolerant to salt stress than either of the tobacco lines with betaine synthesis or AtNHX1. Physiol Plant. 2009;135(3):281-95.

46. Zhao KF, Song J, Fan H, Zhou S, Zhao M. Growth response to ionic and osmotic stress of $\mathrm{NaCl}$ in salt-tolerant and salt-sensitive maize. J Integr Plant Biol. 2010;52(5):468-75.

47. Cheng S, Yang Z, Wang MJ, Song J, Sui N, Fan H. Salinity improves chilling resistance in Suaeda salsa. Acta Physiol Plant. 2014;36(7):1823-30.

48. Sui N, Han GL. Salt-induced photoinhibition of PSII is alleviated in halophyte Thellungiella halophila by increases of unsaturated fatty acids in membrane lipids. Acta Physiol Plant. 2014;36(4):983-92.

49. Li M, Guo S, Xu Y, Meng Q, Li G, Yang X. Glycine betaine-mediated potentiation of HSP gene expression involves calcium signaling pathways in tobacco exposed to NaCl stress. Physiol Plant. 2014;150(1):63-75.

50. Liu Y, Song Y, Zeng S, Patra B, Yuan L, Wang Y. Isolation and characterization of a salt stress-responsive betaine aldehyde dehydrogenase in Lycium ruthenicum Murr. Physiol Plant. 2018;163(1):73-87.

51. Luo D, Niu X, Yu J, Yan J, Gou X, Lu BR, Liu Y. Rice choline monooxygenase (OsCMO) protein functions in enhancing glycine betaine biosynthesis in transgenic tobacco but does not accumulate in rice (Oryza sativa L. ssp. japonica). Plant Cell Rep. 2012;31(9):1625-35.

52. Mansour MMF, Ali EF. Evaluation of proline functions in saline conditions. Phytochemistry. 2017;140:52-68.

53. Sun ZB, Qi XY, Wang ZL, Li PH, Wu CX, Zhang H, Zhao YX. Overexpression of TsGOLS2, a galactinol synthase, in Arabidopsis thaliana enhances tolerance to high salinity and osmotic stresses. Plant Physiol Biochem. 2013; 69:82-9.

54. Guan M, de Bang TC, Pedersen C, Schjoerring JK. Cytosolic glutamine Synthetase Gln1;2 is the Main Isozyme contributing to GS1 activity and can be up-regulated to relieve ammonium toxicity. Plant Physiol. 2016;171(3):1921-33.

55. Wei Y, Shi A, Jia X, Zhang Z, Ma X, Gu M, Meng X, Wang X. Nitrogen Supply and Leaf Age Affect the Expression of TaGS1 or TaGS2 Driven by a Constitutive Promoter in Transgenic Tobacco. Genes. 2018;9(8):1-18.

56. Lo Cicero L, Madesis P, Tsaftaris A, Lo Piero AR. Tobacco plants overexpressing the sweet orange tau glutathione transferases (CsGSTUs) acquire tolerance to the diphenyl ether herbicide fluorodifen and to salt and drought stresses. Phytochemistry. 2015;116:69-77.

57. Khedia J, Agarwal P, Agarwal PK. AINAC4 transcription factor from halophyte Aeluropus lagopoides mitigates oxidative stress by maintaining ROS homeostasis in transgenic tobacco. Front Plant Sci. 2018;9:1522.

58. Kong LA, Xie Y, Hu L, Si JS, Wang ZS. Excessive nitrogen application dampens antioxidant capacity and grain filling in wheat as revealed by metabolic and physiological analyses. Sci Rep. 2017;7:1-14.

59. Sui N. Photoinhibition of Suaeda salsa to chilling stress is related to energy dissipation and water-water cycle. Photosynthetica. 2015;53(2):207-12.

60. Negi NP, Shrivastava DC, Sharma V, Sarin NB. Overexpression of CuZnSOD from Arachis hypogaea alleviates salinity and drought stress in tobacco. Plant Cell Rep. 2015;34(7):1109-26.

61. Kavitha K, George S, Venkataraman G, Parida A. A salt-inducible chloroplastic monodehydroascorbate reductase from halophyte Avicennia marina confers salt stress tolerance on transgenic plants. Biochimie. 2010;92(10):1321-9.

62. Qi YC, Liu WQ, Qiu LY, Zhang SM, Ma L, Zhang H. Overexpression of glutathione S-transferase gene increases salt tolerance of arabidopsis. Russ J Plant Physiol. 2010;57(2):233-40.

63. de Melo LG, Vargas HO, Pizzo de Castro MR, Watanabe MA, Guembarovski RL, Maes M, Nunes SO. Genetic polymorphisms by deletion in genes that encode for glutathione S-transferases are associated with nicotine dependence and tobacco use-related medical disorders. Neuro Endocrinol Lett. 2015;36(6):529-38.

64. Li K, Pang CH, Ding F, Sui N, Feng ZT, Wang BS. Overexpression of Suaeda salsa stroma ascorbate peroxidase in Arabidopsis chloroplasts enhances salt tolerance of plants. S Afr J Bot. 2012;78:235-45.

65. Pang $\mathrm{CH}$, Li K, Wang BS. Overexpression of SsCHLAPXs confers protection against oxidative stress induced by high light in transgenic Arabidopsis thaliana. Physiol Plant. 2011;143(4):355-66. 
66. Bharti P, Mahajan M, Vishwakarma AK, Bhardwaj J, Yadav SK. AtROS1 overexpression provides evidence for epigenetic regulation of genes encoding enzymes of flavonoid biosynthesis and antioxidant pathways during salt stress in transgenic tobacco. J Exp Bot. 2015;66(19):5959-69.

67. Jing X, Hou P, Lu Y, Deng S, Li N, Zhao R, Sun J, Wang Y, Han Y, Lang T, et al. Overexpression of copper/zinc superoxide dismutase from mangrove Kandelia candel in tobacco enhances salinity tolerance by the reduction of reactive oxygen species in chloroplast. Front Plant Sci. 2015;6:23.

68. Singh N, Mishra A, Jha B. Over-expression of the peroxisomal ascorbate peroxidase (SbpAPX) gene cloned from halophyte Salicornia brachiata confers salt and drought stress tolerance in transgenic tobacco. Mar Biotechnol. 2014;16(3):321-32.

69. Liu YX, Zhao HP, Wang ZW, Li YH, Song HB, Riches H, Beattie D, Gu YC, Wang QM. The discovery of 3-(1-aminoethylidene)quinoline-2, $4(1 \mathrm{H}, 3 \mathrm{H})$ dione derivatives as novel PSII electron transport inhibitors. Mol Divers. 2013;17(4):701-10.

70. Liu XX, Fu C, Yang WW, Zhang Q, Fan H, Liu J. The involvement of TsFtsH8 in Thellungiella salsuginea tolerance to cold and high light stresses. Acta Physiol Plant. 2016;38:62(1-9).

71. Yuan F, Lyu MJA, Leng BY, Zheng GY, Feng ZT, Li PH, Zhu XG, Wang BS. Comparative transcriptome analysis of developmental stages of the Limonium bicolor leaf generates insights into salt gland differentiation. Plant Cell EnvironS. 2015;38(8):1637-57.

72. Shen $X Y$, Wang ZL, Song XF, Xu JJ, Jiang CY, Zhao YX, Ma CL, Zhang $H$. Transcriptomic profiling revealed an important role of cell wall remodeling and ethylene signaling pathway during salt acclimation in Arabidopsis. Plant Mol Biol. 2014;86(3):303-17.

73. Sakuma Y, Liu Q, Dubouzet JG, Abe H, Shinozaki K, Yamaguchi-Shinozaki K. DNA-binding specificity of the ERF/AP2 domain of Arabidopsis DREBs, transcription factors involved in dehydration- and cold-inducible gene expression. Biochem Biophys Res Commun. 2002;290(3):998-1009.

74. Yang H, Yu C, Yan J, Wang X, Chen F, Zhao Y, Wei W. Overexpression of the Jatropha curcas JCERF1 gene coding an AP2/ERF-type transcription factor increases tolerance to salt in transgenic tobacco. Biochemistry Biokhimiia. 2014;79(11):1226-36.

75. Yao W, Wang L, Zhou B, Wang S, Li R, Jiang T. Over-expression of poplar transcription factor ERF76 gene confers salt tolerance in transgenic tobacco. J Plant Physiol. 2016;198:23-31.

76. Gupta K, Jha B, Agarwal PK. A dehydration-responsive element binding (DREB) transcription factor from the succulent halophyte Salicornia brachiata enhances abiotic stress tolerance in transgenic tobacco. Mar Biotechnol. 2014;16(6):657-73.

77. Xiang XH, Wu XR, Chao JT, Yang ML, Yang F, Chen G, Liu GS, Wang YY. Genome-wide identification and expression analysis of the WRKY gene family in common tobacco (Nicotiana tabacum L.). Yi chuan. 2016;38(9): 840-56.

78. Jia H, Wang C, Wang F, Liu S, Li G, Guo X. GhWRKY68 reduces resistance to salt and drought in transgenic Nicotiana benthamiana. PLoS One. 2015; 10(3):e0120646.

79. Liu X, Song Y, Xing F, Wang N, Wen F, Zhu C. GhWRKY25, a group I WRKY gene from cotton, confers differential tolerance to abiotic and biotic stresses in transgenic Nicotiana benthamiana. Protoplasma. 2016;253(5):1265-81.

80. Han GL, Wang MJ, Yuan F, Sui N, Song J, Wang BS. The CCCH zinc finger protein gene AtZFP1 improves salt resistance in Arabidopsis thaliana. Plant Mol Biol. 2014;86(3):237-53

81. Wang $K$, Ding Y, Cai C, Chen Z, Zhu C. The role of $\mathrm{C} 2 \mathrm{H} 2$ zinc finger proteins in plant responses to abiotic stresses. Physiol Plant. 2019;165(4):690-700.

82. Liu D, Yang L, Luo M, Wu Q, Liu S, Liu Y. Molecular cloning and characterization of PtrZPT2-1, a ZPT2 family gene encoding a Cys2/His2type zinc finger protein from trifoliate orange (Poncirus trifoliata (L.) Raf.) that enhances plant tolerance to multiple abiotic stresses. Plant Sci. 2017; 263:66-78.

83. Vivek PJ, Tuteja N, Soniya EV. CDPK1 from ginger promotes salinity and drought stress tolerance without yield penalty by improving growth and photosynthesis in Nicotiana tabacum. PLoS One. 2013;8(10):e76392.

84. Han N, Lan WJ, He X, Shao Q, Wang BS, Zhao XJ. Expression of a Suaeda salsa vacuolar $\mathrm{H}+/ \mathrm{Ca} 2+$ transporter gene in Arabidopsis contributes to physiological changes in salinity. Plant Mol Biol Report. 2012;30(2):470-7.

85. Jonak C, Nakagami H, Hirt H. Heavy metal stress. Activation of distinct mitogen-activated protein kinase pathways by copper and cadmium. Plant Physiol. 2004;136(2):3276-83.
86. Zhang S, Klessig DF. MAPK cascades in plant defense signaling. Trends Plant Sci. 2001;6(11):520-7.

87. Yang C, Wang R, Gou L, Si Y, Guan Q. Overexpression of Populus trichocarpa Mitogen-Activated Protein Kinase Kinase4 Enhances Salt Tolerance in Tobacco. Int J Mol Sci. 2017;18(10):2090.

88. Zhang Q, Zhao CZ, Li M, Sun W, Liu Y, Xia H, Sun MN, Li AQ, Li CS, Zhao SZ, et al. Genome-wide identification of Thellungiella salsuginea microRNAs with putative roles in the salt stress response. BMC Plant Biol. 2013;13:1-13.

89. Hajiboland R, Bahrami-Rad S, Akhani H, Poschenrieder C. Salt tolerance mechanisms in three Irano-Turanian Brassicaceae halophytes relatives of Arabidopsis thaliana. J Plant Res. 2018;131(6):1029-46.

90. Yang T, Xu ZP, Lv R, Zhu LS, Peng QD, Qiu L, Tian ZH, Lin HH, Xi DH. N gene enhances resistance to Chilli veinal mottle virus and hypersensitivity to salt stress in tobacco. J Plant Physiol. 2018;230:92-100.

91. Kuluev B, Mikhaylova E, Berezhneva Z, Nikonorov Y, Postrigan B, Kudoyarova $\mathrm{G}$, Chemeris A. Expression profiles and hormonal regulation of tobacco NtEXGT gene and its involvement in abiotic stress response. Plant Physiol Biochem. 2017;111:203-15.

\section{Publisher's Note}

Springer Nature remains neutral with regard to jurisdictional claims in published maps and institutional affiliations.

\section{Ready to submit your research? Choose BMC and benefit from:}

- fast, convenient online submission

- thorough peer review by experienced researchers in your field

- rapid publication on acceptance

- support for research data, including large and complex data types

- gold Open Access which fosters wider collaboration and increased citations

- maximum visibility for your research: over $100 \mathrm{M}$ website views per year

At BMC, research is always in progress.

Learn more biomedcentral.com/submissions 